\title{
Group technology considerations for manufacturing systems with balanced flexibility
}

\author{
Dr. J. Zelený, Dr. P. Grasa S.
}

Professors, Dept. Sistemas de Manufactura, ITESM - CEM Instituto Tecnologico y de Estudios Superiores de Monterrey, campus Estado de Mexico, apdo postal 50, 52926 Atizapan , Estado de Mexico, Mexico. Tel. ( 52 5) 32655 55, fax (52 5) 3265789, e-mail 148.241.44.81

\begin{abstract}
The paper is devoted to a special class of manufacturing systems with limited and balanced technological flexibility. The technologic limitation consists in selection of technologically similar classes of workpieces for machining in a particular manufacturing configuration and in elimination of special or "difficult " parts from the automated part of the process. The special approach, described in this paper looks for classes of workpieces with very similar or even uniform handling surfaces. Unification of external handling surfaces simplifies considerably the function of handling and transport devices within the manufacturing system and avoids the use of interchangeable grippers. This makes the system more robust, reliable, practical and economical.

Within the paper, three particular flexible manufacturing systems with unified handling surfaces of workpieces, tools and fixtures are described as examples .
\end{abstract}

\section{Keywords}

Computer aided design / manufacture, flexible manufacturing cell, flexible manufacturing line, flexible manufacturing system, group technology

\section{INTRODUCTION}

\section{Flexible manufacturing systems}

Flexible manufacturing systems, together with highly efficient CAD-CAM methods for generation of geometric and technologic data for automated production of complex mechanical parts belong presently to the most progressive industrial applications of computer technologies. Flexibility of manufacturing processes has many aspects and limits. It is often interpreted as the ability of the production system to readapt its parameters and structure and change easily to manufacturing of a new class of products. Another, probably more practical, interpretation could be the ability of the system to produce in a random sequence different types of parts without changing its parameters and structure. 


\section{Group technology}

Group technology analyses the spectrum of geometrically and technologically similar parts which can be economically produced in particular manufacturing configurations. Geometric similarity can be very important for machining of parts on conventional, hand controlled machines. Nevertheless, with the introduction of $\mathrm{CNC}$ machines and $\mathrm{CAD} / \mathrm{CAM}$ programming methods, the generation of geometric data even for very different and very sophisticated parts, has been greatly simplified, and the close geometric similarity within the part "families" has lost its previous significance. New concepts in the area of group technology analyze and evaluate the width of technology of common $\mathrm{CNC}$ machines, flexible cells, lines or systems and select the families of parts for maximum utilization of inherent flexibility of numerical control, making simultaneously full use of the available width of technology of CNC machines. General filosophy of group technology approach has been published by Bednarek (1994) in the contribution 2. Special group technology approaches for CNC machining centers and flexible manufacturing systems have been published by Zeleny (1984) in the reference 4 .

\section{Automation}

Automation seeks for production means and methods of elimination or substantial reduction of manpower from the production process and maximization of productivity by introduction of new technologies and intensification of production processes. Regularity, homogeneity and controllability of automated processes contribute significantly to their long-term stability and to the quality of final products.

\section{Batch organization}

In conventional metalworking production, parts are produced in batches and stored for later assembly of final products. Any conventional machine producing a batch of identical workpieces performs a regular operation for a certain "homogenous" period of time and this is probably the main advantage of the batch - type of organization. Any "switch-over" to another type of workpiece means interruption of the homogenous period, loss of time and organizational irregularity. From this point of view, the homogenous periods should be kept as long as possible, with the highest desirable numbers of identical workpieces in every batch. This contradicts to the time and costs of storing the parts for later assembly. Moreover, the production has to be planned months ahead and adaptation to changing market demands is difficult.

\section{Flexible automation}

In the area of CNC machining, we often speak about flexible automation, which tries to apply automation principles even for processes which actually are very irregular, heterogenous and nearly incontrollable. Flexible automation tries to reach new, higher levels of homogeneity in the midvolume production of parts. $\mathrm{CNC}$ machining centers can be equipped with high- capacity tool magazines which makes it possible to machine any time and in any sequence different types of technologically similar workpieces. Machines can change fully automatically to another type of workpieces within quite a broad technologic "family", without attendance or intervention of operators, making use of the stored tools and stored or communicable program data. Worn tools can be monitored and periodically replaced without interruption of the automatic and homogenous regime of the machine. With this achievement of flexible automation, the batch type organization of mid- volume production can be overcome and mechanical parts for the assembly of final products can be manufactured in a "just-in- time" regime, with random-type flow of parts, following the needs of the assembly. 


\section{Systems with balanced flexibility}

The just described new philosophy of flexible automation can be directly applied to autonomous $\mathrm{CNC}$ machining centers for prismatic workpieces or autonomously operating CNC turning centers for rotary parts with additional "prismatic" operations. Nevertheless, there exists a serious problem connected with the manipulation of parts. Parts within the technologic family may have very different geometric forms, dimensions and shapes. Moreover, parts change their shape during the machining process and the final shape may differ significantly from the shape of the input material. If the parts are handled by a human operator, the machine keeps full "random" flexibility within the whole technologic family of parts due to the intelligence and adaptability of the operator. Automation of handling operations is highly desirable for "round the clock" operation of machines, but no robot or manipulator has enough adaptability to replace a human operator in the permanently changing conditions of random- type flexible production. Among other possibilities, the development of "balanced" manufacturing systems with limited flexibility may represent an adequate and practical approach to the implementation of flexible manufacturing systems with random-type operation into the mid-volume production of parts. Within this paper, some special approaches will be discussed and demonstrated in this area.

\section{GROUP TECHNOLOGY CONSIDERATIONS}

Automation of handling processes in mid volume, flexible production of parts is a very difficult problem which cannot be solved in general. Nevertheless, there are solutions for some particular classes of parts. Let us mention at least some of them:

- For small rotary parts with additional prismatic surfaces, it is possible to use bar-type CNC turning centers with contra- spindles and perform all the turning and "prismatic "operations from both sides within one highly integrated machining process. The bar can serve as input material for all parts of the technologic family which is in this case limited mainly by the diameter of the bar. Finished parts are mixed, have different shapes and cannot be automatically manipulated. They have to be sorted and handled manually for further operations or assembly.

- For medium-size rotary parts with no additional prismatic surfaces, it is possible to develop and use self- centering or automatically exchangeable grippers for manipulation of both the input materials and finished parts. Batch-type regime with adequate batch sizes is here recommendable rather than a pure random operation. Further automatic handling of pieces, stored and sorted in transport pallets, is here possible.

- For smaller prismatic parts in bigger- volume production, the batch-type regime with adequate batch sizes is recommendable. A robot or manipulator with an automatically exchangeable batch-dedicated gripper may be used for handling the parts to and from batchdedicated fixtures placed permanently on the machine table or fixed to technologic pallets and exchanged automatically by pallet changing equipment. Production configurations of this type are recommendable only for a very limited variety of parts because of high costs of batch dedicated fixtures and grippers.

- Medium- or bigger-size box-like workpieces with a high variety of technologic operations also need a high variety of tools. For this class of workpieces, the system should be equipped with automatic handling and transport of tools between the tool room and tool magazines of installed machining centers. Homogenous regime of this flexible manufacturing system with random flow of parts and tools may include the automatic reconfiguration of stored tools. 
Flexibility of these systems has to be "balanced" and optimized between the problematic need of ideal flexibility and costs of the stored tools and the tool transport system.

- In some special cases, some technologic families of workpieces with inherent uniformity of handling and clamping surfaces can be found and selected for automatic production, avoiding the necessity of technologic pallets. Important condition for realization of such systems is the invariability of uniform handling (and if possi ble also clamping) surfaces throughout the whole process of automatic machining and manipulation. Manufacturing systems with uniform handling and clamping surfaces can reach the highest level of flexibility and effectivity and make possible a random flow of free, unclamped parts throughout the manufacturing area. Number of fixtures and technologic pallets is reduced to a minimum. Piece- or batch- dedicated tooling is fully eliminated.

\section{RESEARCH AND REALIZATION}

Three examples of systems described above last two point will be shown within this paper, these being:

- System A: The flexible manufacturing cell for automized production of a broad family of ISO 40 - cone tools and tooling parts.

- System B: The flexible manufacturing line for flexible production of multicolored PVC parts with CNC machining of molds.

- System $C$ :The flexible manufacturing system with random flow of parts and tools with the highest degree of technological flexibility in production of medium size, box-like, cast iron parts.

\section{Realization}

- Research and realization of the system $\mathrm{A}$ is being performed at the ITESM-CEM Instituto Tecnologico y de Estudios Superiores de Monterrey - Campus Estado de Mexico, Mexico. Realization is being prepared within the laboratories of the department "Sistemas de manufactura" of the ITESM - CEM. The basic configuration of the system has been described by Grasa ,Chavoya (1993) and Zeleny (1994) as quoted in references 3 and 6.

- Research of the system B has been performed by the INSTITUTO DE INGENIERIA UNAM in Mexico, D.F. The system has been described in more detail by Zeleny (1995) in the reference 7. General state of art in production of molds has been published by Altan and coauthors (1993) in the reference 1.

- Research and development of the manufacturing system $C$ has been performed in the VUOSO Research institute of machine tools and machining in Praha (Czech Republic). The system had been repeatedly realized in four Czech plants these being the TOS - OLOMOUC machine tool plant, the TOS - CELAKOVICE machine tool plant, the OSTROJ - OPAVA mine machine plant and the TRANSPORTA - CHRUDIM transport machine plant. A more detailed description and realization of these system has been published by Zeleny (1993) as quoted in references 4 and 5 .

\section{FLEXIBLE MANUFACTURING CELL - SYSTEM A}

\section{Technology}

Recent revolutionary development in tools, tool holders and tool inserts for milling, drilling, boring and turning operations opened new application areas for most progressive CNC technologies. Technology of the system A is based on an integration of a CNC lathe with a multi- 
axis "prismatic" machining center, both installed in the laboratories of the department "sistemas de manufactura" in the ITESM.

\section{Technologic family of workpieces:}

Tools, tool holders and tool bodies with the ISO 40 cone.

\section{Main ideas}

- Using the handling grooves of the future tools as the uniform handling surfaces during their production.

- Using the clamping cones of the future tools as the uniform clamping surfaces for performing of prismatic operations.

- Preparing in advance the interface surfaces on tool bodies, assembling composed (semi finished) tools and letting them enter as family members for automatic machining of tool bodies.

- Preparing in advance only the clamping surface for the first (turning) operation and machining other clamping surfaces within the automatic function of the cell.

\section{Block diagram of technologic operations}

Figure 1 shows the sequence of main operations within the flexible manufacturing cell. Bold lines show the "hard core" of the cell with fully automatic function. Composed tools contain only tool holders and tool bodies, whereas the cutting inserts are assembled manually after machining operations.

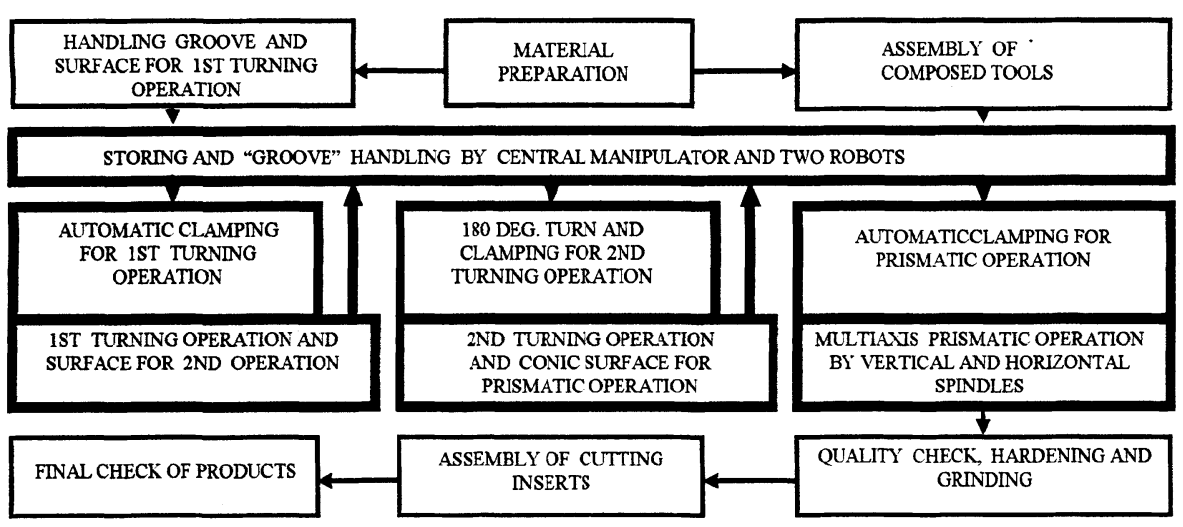

Figure 1 Main technologic operations in the system A.

\section{Lay-out diagram}

Figure 2 shows the system lay-out. Here again, the accented part shows the "hard core" of the system. Central manipulator (type CINCINNATI T3-373) has access to the working space of the lathe, to the fixtures placed on technologic pallets of the machining center, to the cleaning station and to the re-circulating store with 12 recirculating system-pallets. Pallets have multipurpose nests which allow to store free pieces with both cylindrical (for turning) and conic clamping surfaces. Parts can be stored during all phases of the process. Two robots (type IBM7576 "SCARA" industrial robot) serve as an interface to the external transport of parts on transport pallets. 


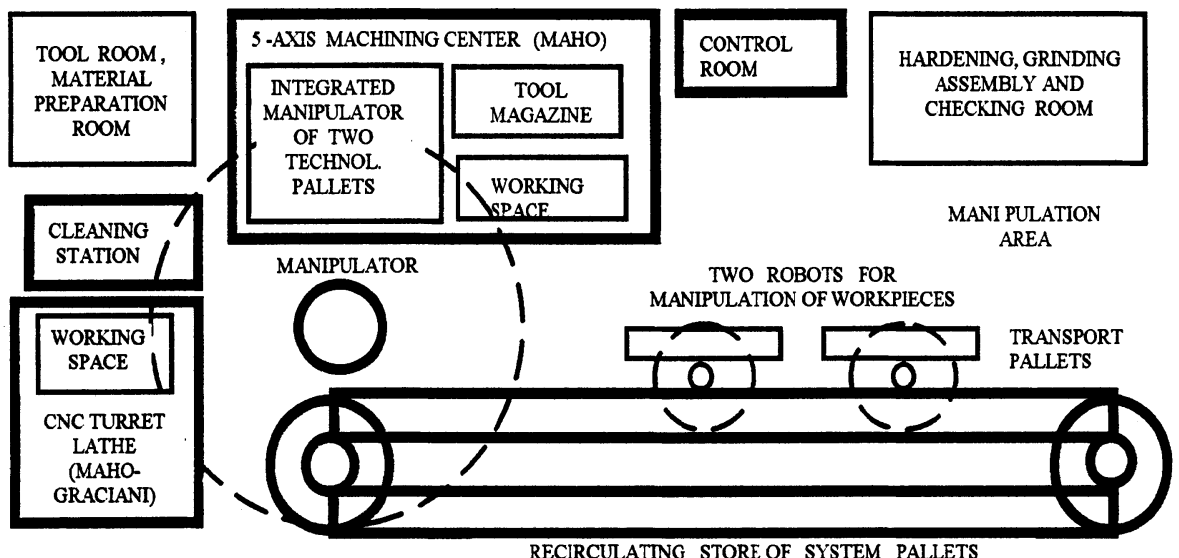

Figure 2 Lay-out of the system A.

\section{FLEXIBLE MANUFACTURING LINE - SYSTEM B.}

\section{Technology}

The rapidly changing market of PVC products needs an unbelievable variety of molds for injection machines and production processes using gravitation technology rather than high-pressure injecting., In applications of the gravitation technology, mono or multicolored fluid plasts are filled into pockets and hollows of flat- shaped molds under atmospheric pressure conditions. Solidification of the fluid, originally cool plastisol material is performed by thermal cycles which include heating and cooling of molds together with the future PVC products.

Technologic family of workpieces: Flat - type aluminum and light alloy molds with uniform external dimensions $500 \times 12.7 \mathrm{~mm}$. Longitudinal dimensions $500,600,700$ or $800 \mathrm{~mm}$.

\section{Main ideas}

- Elimination of transport pallets and circulation of free molds with uniform external dimensions in a recirculating flexible line .

- Using the uniform external surfaces as a reference base for the $\mathrm{CAD} / \mathrm{CAM}$ programming of internal functional surfaces of molds.

- Using the uniform external surfaces as reference clamping surfaces for CNC machining of molds.

- Introduction of protective layers at the beginning of the production process for significant improvement of quality and productivity.

\section{Block diagram of technologic operations}

Figure 3 shows the main technologic operations within the flexible manufacturing line (system B). The main part of the system, ("hard core") shown by bold lines, includes in this case some stations with a lower degree of automation. Typically, the station for colored layers cannot be fully automated for the high degree of flexibility needed for "random" flow of molds with a high variety of internal functional surfaces. A protection layer provides a mono-colored protection of all top 
surfaces of molds. It doesn't enter into hollows reserved for colored layers and protects perfectly all boundaries between mono - and multicolored parts of the final PVC products.

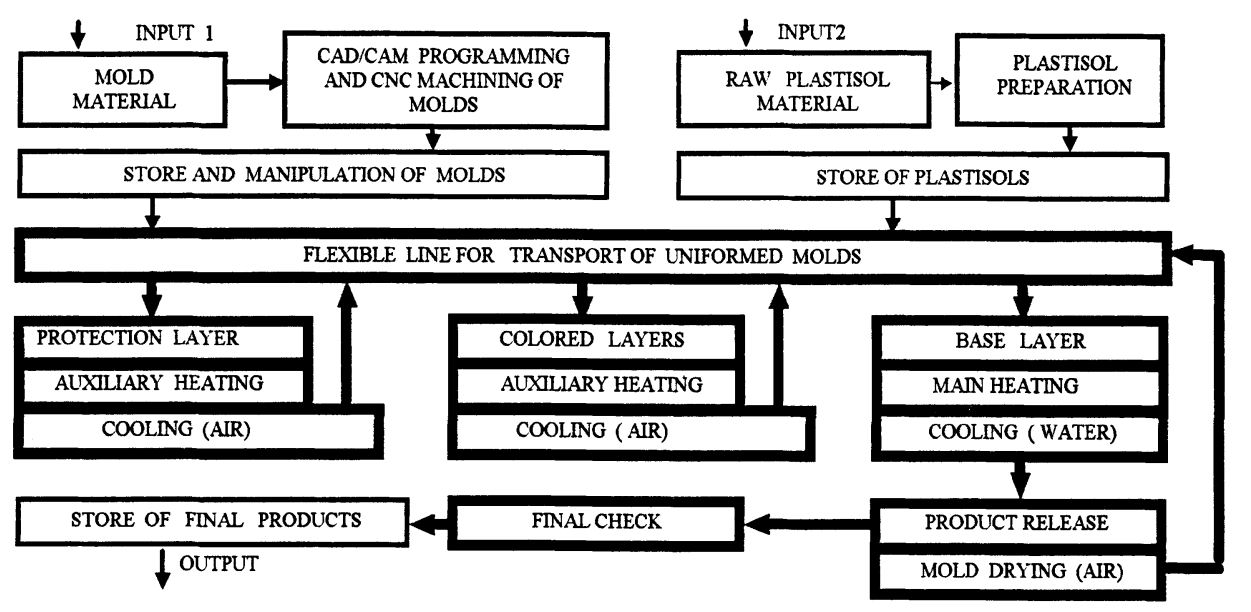

Figure 3 Main technologic operations in the system B.

\section{Lay-out diagram}

Figure 4 shows the layout of the flexible line (system B). CNC machining of molds represents an off-line part of the production system. Also a very important off-line part of the process is the quality check of the plastisol materials at the beginning of the process. Manual manipulation of molds between the store of molds and the protection layer station can change anytime the types of molds circulating within the flexible line.

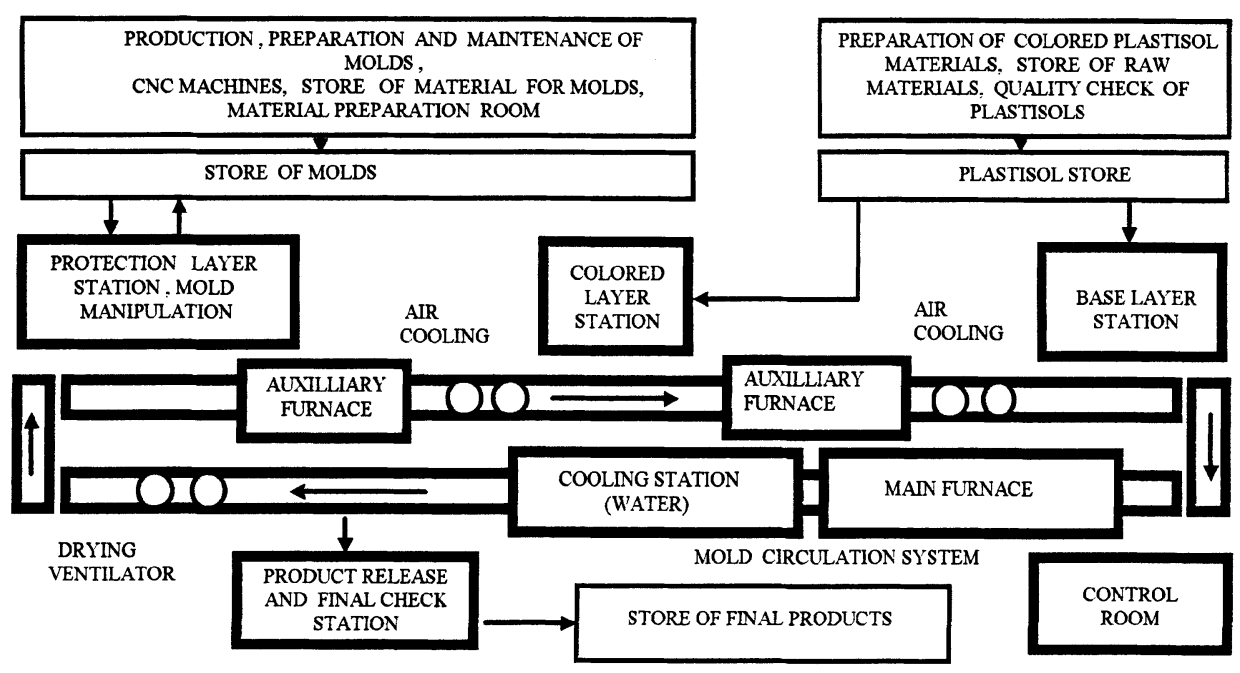

Figure 4 Lay-out of the system B. 


\section{FMS WITH RANDOM FLOW OF PARTS AND TOOLS - SYSTEM C}

\section{Technology.}

Unmanned, "round- the- clock" machining of box-like, cast iron workpieces in flexible manufacturing systems already proved its vitality in many areas of metalworking industries years ago. Machining technology is based on application of $\mathrm{CNC}$ machining centers with horizontal spindles and pallet manipulators. Workpieces are clamped by means of piece-dedicated fixtures on technologic pallets with uniform handling surfaces.

Within the described system, 8 identical machines have been used of the type MCFHD 40 machining centers with horizontal spindles, high-capacity tool magazines and pallet changers. Each machine for this particular FMS application includes a module for in-process measuring of workpieces and tools, a module for automatic in-process control of boring bar diameters and a highcapacity tool magazine for 144 tools. Both the pallet changer and the tool magazine are linked to the external automatic transport of pallets and tools.

\section{Technologic family of workpieces}

Box-like cast- iron workpieces to maximum dimensions of $400 \times 400 \times 400 \mathrm{~mm}$.

\section{Main ideas}

- FMS machining module with "random - type " flexibility in both pallet and tool flows.

- High- capacity tool magazines at the machines (144 tools) for increasing the variety of workpieces within the group technology of the system.

- Automized transport link between the tool magazines and the tool room.

- In- process measuring of tool dimensions and automatic correction of boring bar diameters directly in the machine spindleSoftware for tool life monitoring within the whole tool system (1440 tools) and generation of messages for the tool room .

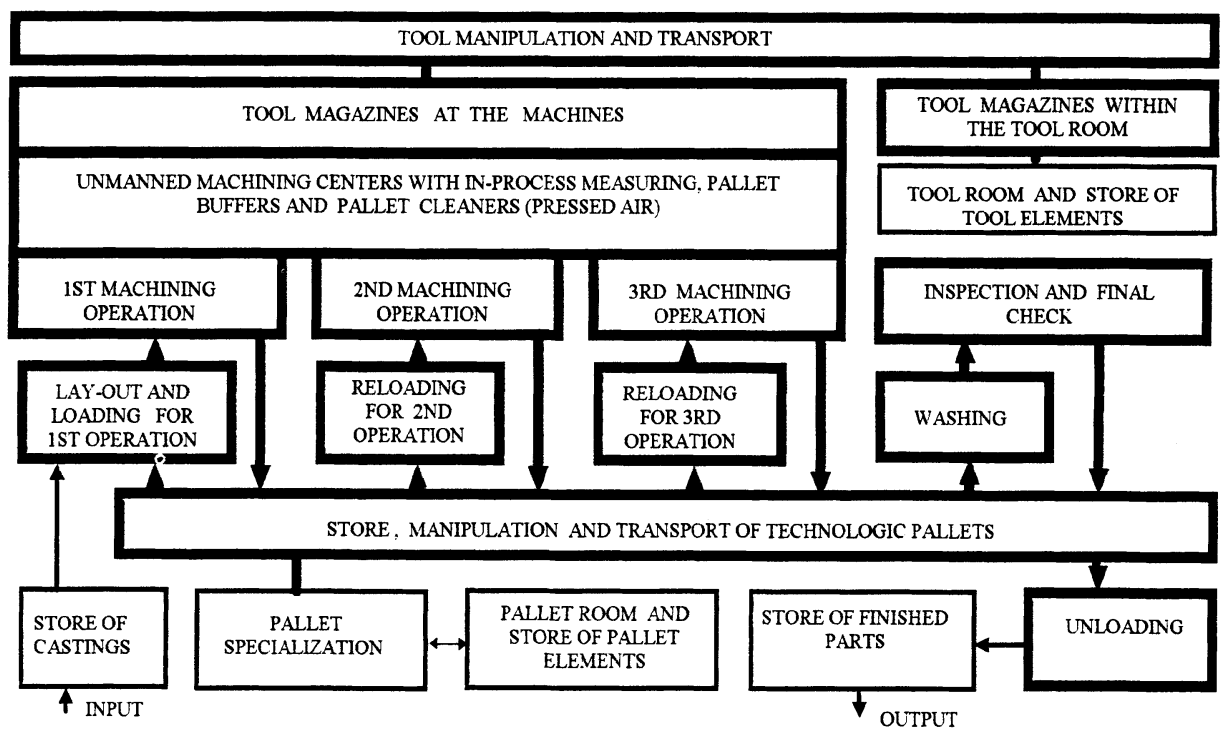

Figure 5 Main technologic operations in the system $\mathrm{C}$. 


\section{Block diagram of technologic operations}

Figure 5 shows the typical sequence of technological operations within the system $\mathrm{C}$. The accented part relates to the area of automatic, "round-the-clock" operation . Machining of parts occurs typically in three operations, with possible exceptions. The system can handle any time any of 200 types of operations, with a reserve of 50 operations within the pallet store capacity (250 pallets). This corresponds to about 70 different workpieces.. Total variety of tools is about 350 tool types for all ttechnologic operations. The rest of the tool system capacity (1440 tools) is reserved for spare- and multiple tools.

\section{Lay-out diagram.}

Figure 6 shows the lay-out of the system $C$ as it has been realized in the TOS-OLOMOUC plant. Localization of individual stations and rooms minimizes the transport routes and considers the safety regulations. In fact, every machine enables access to its working space for inspection and maintenance. Manual manipulation with tools is not practiced with possible exception when verifying new workpieces. Coordinate measuring machines are placed in a special room with stabilized temperature. Palletized workpieces are introduced to this room inmediately after washing by the automatic storage- and retrieval system.

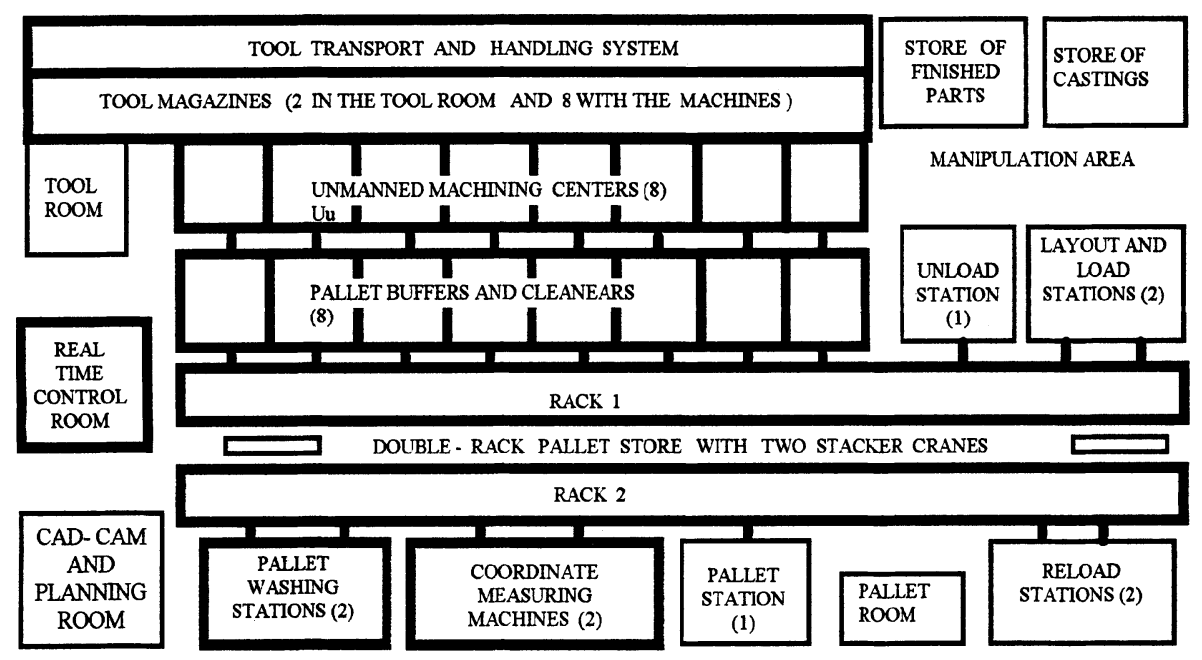

Figure 6 Lay-out of the system C.

\section{CONCLUSIONS}

Group technology considerations are extremely important in conceptual design of flexible manufacturing systems. The paper is devoted to flexibly automated manufacturing constellations with uniform handling and clamping surfaces and random flexibility of operations within the chosen range of technology. This represents certain limitation in the selection of part families and coonceptional design of the system. On the other hand, systems of this class make full use of the computer-flexibility of information processing and real time control of $\mathrm{CNC}$ machines at simultaneous robustness and relative simplicity of handling and transport operations. 
Shown examples from the area of tooling parts (system A), molds for PVC parts (system B ) and box-like cast iron parts (system C) demonstrate cases where hundreds of geometrically different workpieces have uniform handling and clamping surfaces and can be manufactured and handled with considerably simplified and robust handling and tooling devices.

Also, it was the intention of the authors to show that certain engineering limitations and optimizing "balance" in the conceptual design of manufacturing systems create much better chances for highest, random-type flexible automation of quite difficult production processes and for realization of most progressive production philosophies.

\section{REFERENCES}

1 Altan T.,Lilly B. V., Kruth J.P., Koenig W., Toenshoff H.K., Lutterwelt V.A., Khairy A.B. (1993) Advanced technique for die and mold manufacturing . CIRP Annals "Manufacturing Technology" , (with other 103 bibliography items).

2 Bednarek M. (1994) Tecnologia de grupos, la clave para la implementación del CIM. AGT Editor, Mexico.

3 Grasa P. S., Chavoya O. (1993) Integración de una celda flexible de manufactura. Revista de Ingenieria de la Universidad de Costa Rica, vol. III, No. 1.

4 Zeleny J. (1984) Unmanned technology and control strategies in flexible manufacturing systems with random flow of parts and tools. CIRP conference on manufacturing technology, Palermo.

5 Zeleny J. (1993) Flexible manufacturing systems with random flow of parts and tools. XIX. Congreso de Academia Nacional de Ingeniería, Acapulco.

6 Zeleny J. (1994) Robotized flexible manufacturing cell for 5-dimensionally complex parts in tooling technologies " Internal report, ITESM-CEM, Mexico.

7 Zeleny J. (1995) CAD / CAM machining of molds and intelligent manufacturing of multolored PVC parts by gravitation technology", First World Congress of Intelligent Manufacturing Processes and Systems, University of Puerto Rico.

\section{BIOGRAPHY}

Dr. Jaromir ZELENY got his MSc in 1953 and his $\mathrm{PhD}$ in 1961, both from the CVUT Prague. He was researcher, head of research departments and vicepresident of the VUOSO Research Institute of Machine Tools in the period 1952 - 1991. He directed 8 succesful governmental projects in NC machines, CNC controls and FMS and was coordinator of research activities in the czechoslovak machine tool industry. He directed $20 \mathrm{PhD}$ theses, published 80 papers/articles and got 78 industrial patents. He is active member of CIRP since 1974. He was lecturer, Professor and researcher at the CVUT, Michigan State University and UNAM and currently is Professor at the ITESM - CEM in Mexico.

Dr. Pedro GRASA Soler got his Bsc from the UNAM, Msc from theUniversite de Bordeaux and PhD from the Université de Nancy. He was Professor and Chief of Department at the UAM and participated in 7 research projects in the UAM and in the Automatics Research Center in Nancy. He has also been director of the Manufacturing Research Center and Technology and Productivity Center in the ITESM-CEM. He published 20 research reports and directed $19 \mathrm{Msc}$ theses. He received the Golden Ram award in the ITESM-CEM and candidates for National Researcher. He is now Professor and director of theDivision for Graduate Studies and Research at the ITESM - CEM. 